ISSN 1870-4069

\title{
Ramath: Mobile Application for Math Learning using Augmented Reality
}

\author{
Hiram David Cortés Díaz ${ }^{1}$, Octavio Elías Piñal Ramírez ${ }^{1}$, \\ Amadeo José Argüelles Cruz ${ }^{1}$, Claudia Marina Vicario Solórzano ${ }^{2}$ \\ 1 Instituto Politécnico Nacional, Centro de Investigación en Computación, \\ Mexico City, Mexico \\ 2 Instituto Politécnico Nacional, Unidad Profesional Interdisciplinaria de Ingeniería y \\ Ciencias Sociales y Administrativas, Mexico City, Mexico \\ hcortesd1200@alumno.ipn.mx, opinalr1200@alumno.ipn.mx, jamadeo@ipn.mx, \\ cvicario@ipn.mx
}

\begin{abstract}
This paper presents a mobile application (app) using Augmented Reality (AR) with the support of game play mechanics in a non-game application, oriented to help 12 to 15 year's old students to learn several math subjects. We associate concepts such as gamification and Problem-Based Learning (PBL) within the app, making the subjects much more interesting to the students and encouraging them to be fearless of math by taking advantage of the human's psychological predisposition to engage in gaming. With the collected information from the research and the help of a predictive algorithm, we try to show how much the technology can help in education.
\end{abstract}

Keywords: augmented reality, mathematics, gamification, mobile application, learning tool, predictive model, education.

\section{Introduction}

"When will I use math?" is a question often posed by students form elementary to high school, wondering how topics they see in school will play a role in the everyday life. In recent years there is a tendency in most of the students in the world, they consider subjects like mathematics and science hard, complex and unnecessary as they can't see how they could use them. Because of that, careers oriented on these subjects seem to have a low demand, which could be a problem in the development of science [1].

There are tests designed to measure the level of knowledge of the students in the basic level (elementary - high school) in maths and Spanish. These tests are a good starting point to analyze the performance in these subjects and what can we do to help students improve. According to the Organization for Economic Co-operation and Development (OECD) only 1\% of the 15 years old Mexican students have good grades in math and science [2]. According to Plan Nacional para las Evaluaciones de los Aprendizajes (PLANEA) only 6.3\% of all Mexican students have an acceptable performance in mathematics [3]. 
It seems right to use interactive activities that, with the help of technology, can help and allow a better understanding of maths so students can get attracted and see how they can be used outside the classroom. Augmented reality (AR) and problem-Based Learning (PBL) approach could make a good fit to design the lessons and the way to navigate through them, also, gamification could help us to attract the students, making the lessons more engaging and interesting.

The remainder of this papes is structures as it follows. In section 2 we mention and describe some works similar to ours, commenting their main characteristics. In section 3 we define some of the concepts relevant to our work and specify how and where we apply it, as well as the specifications of the tests. Section 4 presents the results of the tests performed. Finally ection 5 concludes and gives the highlights of the findings.

\section{Related Work}

The scope of this paper is the development of an AR app for educational proposes in math subjects. Previous works have already considered the use of AR in this field. For example, Kaur et al. [5] developed an AR web-based application with the proposal of teaching 3D geometry concepts and improve the visualization abilities of middle school students. The study of Hanafi et al. [6] suggest that the AR could improve the motivation in learning subjects because of the lack of confidence and practice. Similar implementation to Ramath is the work of [7], their results suggests that the use of AR generates enthusiasm in the students and also remarks the accessibility and ease of use of the application.

The relationship of AR and education is addressed in the work of Hsin-Kai $\mathrm{Wu}$ et al. [8] they suggest that the AR could help learners to engage in an authentic exploration of the real world, and virtual objects such as texts, videos, $3 \mathrm{D}$ models and pictures are supplementary elements for learners to conduct investigations of the real-world surroundings. Second, the use of AR technologies can extend to integrating real-world and digital learning resources. The idea is not to replace traditional learning but use AR as a complementary tool.

Meta-Analysis studies were conducted between 1992 and 2011 to compare the effects of games and simulations with traditional classroom instruction based on students' performance. The work of Dimitrov et al. [9] comprises 67 studies and their major findings were that $56 \%$ of the experiment population showed no difference between games and conventional instruction but $32 \%$ favoured games, while $5 \%$ favoured conventional instruction. The analysis made by Wolfe et al. [10] comprises 7 studies; they found out that games are rated as more interesting that conventional instruction. Game-based approach produced significant knowledge-level increases over the conventional case-based teaching methods.

In the work of Hays et al. [11] they analyzed 105 different studies, their major findings were that an instructional game will only be effective if it meets specific instructional objectives and used as it was intended. Instructional games should be embedded in instructional programs that include debriefing and feedback. The use of instructional support help learners to understand how to use the 
game increases instructional effectiveness of the gaming experience. At the same time, instructional designers are needed to design games.

Vogel et al. [12] analyzed 32 studies, they found that higher cognitive gains were observed in subjects using interactive games versus traditional teaching methods (although simulations yielded a stronger result). Better attitudes toward learning when compared to traditional teaching methods. Level of picture realism in the computer program does not seem to have an impact.

Ke et al. [13] made an analysis of 600 studies and they showed that the effects of learning with games was positive in $52 \%$ of the studies examined. Stizmann et al. [14] found out, after analyzing 65 studies, that confidence with games 20 percent higher. Declarative knowledge was $11 \%$ higher for trainees taught with simulation games. Procedural knowledge was $14 \%$ higher with simulation games. Retention was $9 \%$ higher with simulation games.

These studies show that the use of games can help to improve learning, we can use these ideas in math, because of the abstract nature of this subject using augmented reality as a visual representation of the contents present a good chance to implement it. AR can be involved in adding complementary information to texts, books or any material used in classrooms or to add interactivity between the students and the object of study and enriches the educational environment.

\section{Materials and Methods}

Ramath is an AR-based mobile application for visualization of theoretical and practical information about three specific subjects: Geometric figures, Pythagoras theorem and operations with fractions. Concepts and problems are represented with dialogue globes and 3D figures. Each topic begins with a problem that needs to be solved. To solve the problem, the student needs to go through every lesson that explain a specific concept to solve the initial problem. After seeing every lesson, the student will try to solve the initial problem, with the option of going back into the lessons to consult any concept.

\subsection{Augmented Reality}

AR is the technology that enriches the real world with digital information and multimedia, such as 3D models and videos, overlaying in real-time the camera view of your smartphone, tablet, $\mathrm{PC}$ or glasses [15].

Ramath uses QR codes as targets that users need to focus with the mobile's camera, so it will pop the information and 3D figures associated to it, as seen in Fig.2. Each target has a specific lesson of a specific subject, for example, there's a target that shows how to calculate the volume of a pyramid. Once the information and 3D figures has been popped, the user can move freely in the space to visualize the information and figures in different angles. 


\subsection{Problem-Based Learning}

Problem-Based Learning (PBL) is a teaching method, with the use of complex real-world problems as the vehicle to promote student learning of concepts and principles as opposed to a direct presentation of facts and concepts. Besides course content, PBL can promote the development of critical thinking skills, problem-solving abilities, and communication skills [16].

In Ramath, we use PBL to define the structure of the lessons and the order of appearance. In every subject, we show the main problem that needs to be solved, as seen in Fig. 1. After that the app shows all the concepts, formulas and some examples that are needed to solve the problem, as seen in Fig. 2. Finally the main problem is showed but now with some answers that we can choose, as seen in Fig. 3. In the case that the answer is incorrect, we can try again or return to some of the concepts, formulas and examples.

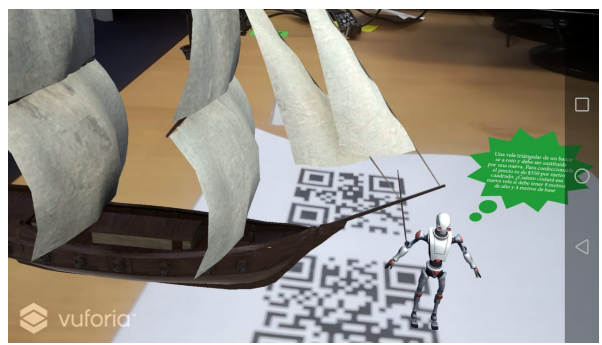

Fig. 1. Main problem to solve.

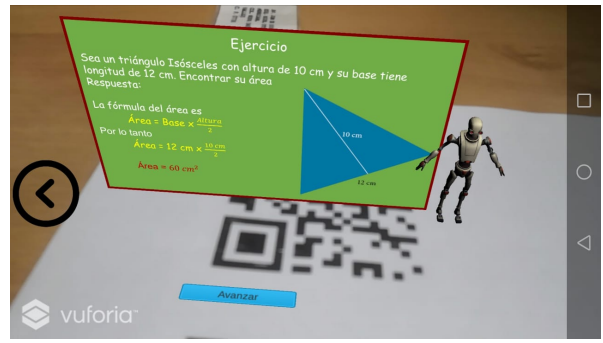

Fig. 2. Concepts.

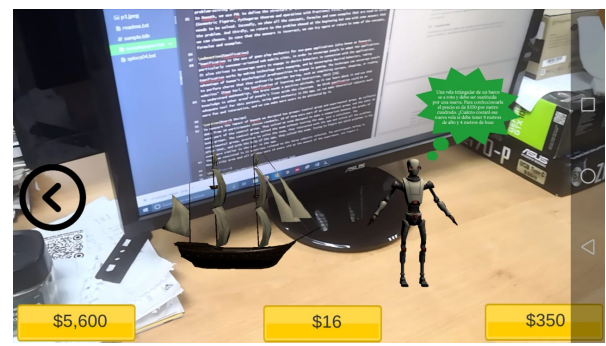

Fig. 3. Trying to solve the main problem.

\subsection{Gamification}

Karl Kapp defines gamification as "the use of game play mechanics for non-game applications in order to encourage people to adopt the applications. It also 
strives to encourage users to engage in desire behaviors in connection with the applications. Gamification works by making technology more engaging, and by encouraging desired behaviors, taking advantage of human's psychological predisposition to engage in gaming. The technique can encourage people to perform chores that they ordinarily consider boring, such as surveys, shopping, or reading websites" (Kapp Karl, The Gamification of learning and Instruction, 2012) [17] To understand mathematics, the brain needs a positive attitude, so it can learn about it and use that knowledge in other areas of people's lives aside the classroom. Gamification could be an adequate tool for this purpose, using game mechanics in the app, we can make theoretical subjects much more fun and interactive, and we can make more users to be attracted by it.

\subsection{Research Design}

To measure the impact of Ramath we designed two groups: Control and experimental group. We collected data from 20 participants chosen randomly, 10 of them were part of an experimental group, and the other 10 were part of the control group, all of them belong to Mexico City and were 14 years old at the moment of the test, see Fig. 4. They solved an exam that consisted on 11 questions related to the subjects selected to make a comparison between the grades of both groups. The control group solved the exam without using the app. The experimental group, interacted with the app and used the contents to solve the exam.

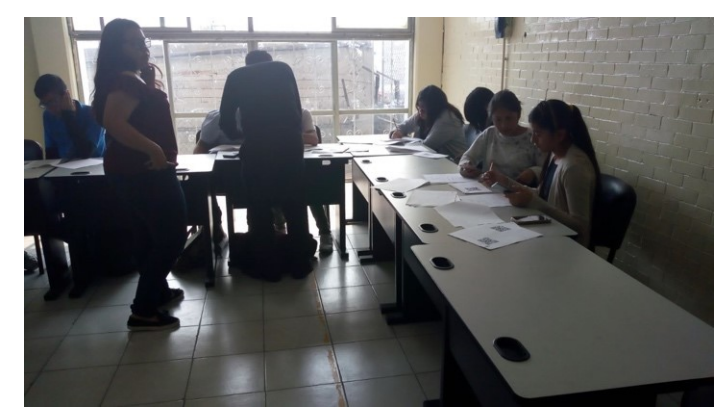

Fig. 4. Control and Experimental group.

The variables identified in this case study were

- Dependent Variable: Student's grades.

- Independent Variable: Ramath's use.

- Quantitative Variable: Grades from the test exam.

Statistic Analysis We used linear Regression Model to make a prediction of how much Ramath's users can raise their grades in school. It allows to find the 
expected value of a random variable "a" when "b" takes a specific value [18]. This model has the problem that every result obtained from it will be linear, but grades from the students are never linear, so we opted to use Holt's trend method to get a much more precise model.

Holt's trend method Holt (1957) extended simple exponential smoothing to allow forecasting of data with a trend. This method involves a forecast equation "(1)" and two smoothing equations, one for the level "(2)" and one for the trend "(3)" [19]. In "(1)" and "(2)" $C_{x}$ it's the average, $\alpha$ and $\beta$ are the smoothness parameters, $Y_{x}$ the value of the sample. In "(3)" $R_{x}$ it's the expected value.

$$
\begin{gathered}
C_{x}=\alpha Y_{x}+(1-\alpha)\left(C_{x-1}+b_{x-1}\right), \\
b_{x}=\beta\left(C_{x}+C_{x-1}\right)+(1-\beta) b_{x-1}, \\
R_{x}=C_{x}+b_{x} .
\end{gathered}
$$

\section{Results}

In Fig. 5 and Fig. 6 we show the results of both groups. By grades, we mean the last 3 bimonthly grades they obtained in math. We can observe that there is a difference of $1.8 \%$ between the groups in the average of the test results, we can assume that the difference is due to the use of Ramath in a controlled environment.

\begin{tabular}{|c|c|c|c|c|c|}
\hline $\begin{array}{c}\text { Like for } \\
\text { mathematics }\end{array}$ & $\begin{array}{c}\text { Like for } \\
\text { Videogames }\end{array}$ & $\begin{array}{c}\mathbf{1} \\
\text { grade }\end{array}$ & $\begin{array}{c}\mathbf{2} \\
\text { grade }\end{array}$ & $\begin{array}{c}\mathbf{3} \\
\text { grade }\end{array}$ & Test \\
\hline Yes & No & 7.4 & 7.6 & 9 & 4.5 \\
\hline Yes & Yes & 8.3 & 10 & 10 & 4.5 \\
\hline No & No & 10 & 7.9 & 10 & 4.5 \\
\hline Yes & Yes & 9.1 & 8 & 9.5 & 4.5 \\
\hline Yes & No & 8.2 & 10 & 9.5 & 3.6 \\
\hline Yes & Yes & 7.1 & 6 & 8.9 & 3.6 \\
\hline Yes & Yes & 9.6 & 8.1 & 9.8 & 3.6 \\
\hline Yes & Yes & 8.2 & 6.6 & 10 & 3.6 \\
\hline Yes & Yes & 7.1 & 8.4 & 9.1 & 2.7 \\
\hline Yes & Yes & 9.2 & 8.6 & 8.8 & 2.7 \\
\hline \multicolumn{2}{|r|}{ Average } & $\mathbf{8 . 4 2}$ & $\mathbf{8 . 1 2}$ & $\mathbf{9 . 4 6}$ & $\mathbf{3 . 7 8}$ \\
\hline \multicolumn{7}{|r}{} & & \multicolumn{1}{r}{}
\end{tabular}

Fig. 5. Experimental group results.

\begin{tabular}{|c|c|c|c|c|c|}
\hline $\begin{array}{c}\text { Like for } \\
\text { Mathematics }\end{array}$ & $\begin{array}{c}\text { Like for } \\
\text { Videogames }\end{array}$ & $\begin{array}{c}\mathbf{1} \\
\text { grade }\end{array}$ & $\begin{array}{c}\mathbf{2} \\
\text { grade }\end{array}$ & $\begin{array}{c}\mathbf{3} \\
\text { grade }\end{array}$ & Test \\
\hline No & No & 10 & 7.6 & 8 & 6.3 \\
\hline No & No & 8.2 & 7.8 & 6 & 6.3 \\
\hline No & No & 9.2 & 10 & 9.1 & 4.5 \\
\hline No & No & 7.2 & 6.5 & 9 & 4.5 \\
\hline No & Yes & 8.4 & 7.3 & 7.8 & 3.6 \\
\hline No & No & 9 & 10 & 9.8 & 3.6 \\
\hline Yes & Yes & 7.6 & 7.4 & 9.2 & 3.6 \\
\hline Yes & Yes & 10 & 6.3 & 7 & 3.6 \\
\hline Yes & Yes & 9.5 & 9.2 & 9.4 & 0 \\
\hline No & Yes & 7.2 & 7 & 7.5 & 0 \\
\hline \multicolumn{2}{|r|}{ Average } & $\mathbf{8 . 6 3}$ & $\mathbf{7 . 9 1}$ & $\mathbf{8 . 2 8}$ & $\mathbf{3 . 6}$ \\
\hline \multicolumn{7}{|r}{} & & & &
\end{tabular}

Fig. 6. Control group results. 


\begin{tabular}{|c|c|c|c|c|c|}
\hline $\begin{array}{c}\text { Like for } \\
\text { Mathematics }\end{array}$ & $\begin{array}{c}\text { Like for } \\
\text { Videogames }\end{array}$ & $\begin{array}{c}\mathbf{1} \\
\text { grade }\end{array}$ & $\begin{array}{c}\mathbf{2} \\
\text { grade }\end{array}$ & $\begin{array}{c}\mathbf{3} \\
\text { grade }\end{array}$ & Test \\
\hline No & No & 10 & 7.6 & 8 & 6.3 \\
\hline No & No & 8.2 & 7.8 & 6 & 6.3 \\
\hline No & No & 9.2 & 10 & 9.1 & 4.5 \\
\hline No & No & 7.2 & 6.5 & 9 & 4.5 \\
\hline No & Yes & 8.4 & 7.3 & 7.8 & 3.6 \\
\hline No & No & 9 & 10 & 9.8 & 3.6 \\
\hline Yes & Yes & 7.6 & 7.4 & 9.2 & 3.6 \\
\hline Yes & Yes & 10 & 6.3 & 7 & 3.6 \\
\hline Yes & Yes & 9.5 & 9.2 & 9.4 & 0 \\
\hline No & Yes & 7.2 & 7 & 7.5 & 0 \\
\hline \multicolumn{2}{|r|}{ Average } & $\mathbf{8 . 6 3}$ & $\mathbf{7 . 9 1}$ & $\mathbf{8 . 2 8}$ & $\mathbf{3 . 6}$ \\
\hline
\end{tabular}

Fig. 7. Control group results.

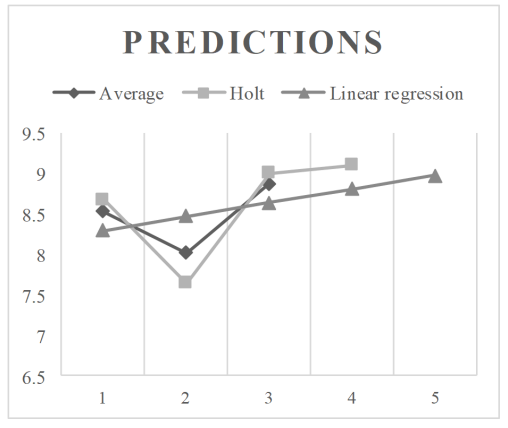

Fig. 8. Comparison of the predictions.

\section{$5 \quad$ Discussion and Conclusions}

After the tests we applied the predictive models to the whole data, not distinguishing between the groups. In Fig. 7 we show the average grades of all the participants with the improvement of the $1.8 \%$ derived from the experiment. We used the grades as data entry for the linear regression and Holt predictive model. With this, we could predict grades up to 2 bimester. In Fig. 7 and Fig. 8 we can see the results of the linear regression model, the Holts predictive model, the comparison of both predictive models and the average grade of all students.

There is an improvement of about $1.8 \%$ between the two groups that made the test. The experimental group was the one with the best results. The only significant difference between the two groups was the use of the app, we assume that the improvement was because of Ramath.

At this point of the research we can not affirm or deny if there is a correlation between the like of video games or mathematics and the results in the test or in the students grades. We will use the predictive models to keep track of students activities, so they will know their performance and to have a better idea of whether prolonged use of the application could improve student grades.

After the experiment we can conclude that in a controlled envorinment technology can help students to rise their grades and have a better understanding of maths, the experiment moves to a phase 2 in which we will work with a larger number of students and in a prolonged period, expecting to improve and replicate the results obtained.

Acknowledgment. The authors of the present paper would like to thank the following institutions for their economical support to develop this work: Consejo Nacional de Ciencia y Tecnología (CONACYT), SNI, Instituto Politécnico Nacional (COFAA, SIP, CIDETEC, and CIC) and Escuela Secundaria Técnica Número 47 "Juan de Dios Batiz". 


\section{References}

1. Randel, J.M., Morris, B.A., Wetzel, C.D., Whitehill, B.V.: The effectiveness of games for educational purposes: a review of recent research. Simulation and gaming 23(3), 261-276 (1992)

2. OCDE: Programa para la Evaluación Internacional de Alumnos (PISA) Resultados, 14. Retrieved from https://www.oecd.org/pisa/PISA-2015-Mexico-ESP.pdf (2016)

3. Educación Básica 2016 Subsecretaría de Planeación, Evaluación y Coordinación Planea Básica 2016 Informe cobertura. (n.d.). Retrieved from: http://planea.sep.gob.mx/content/general/docs/2016/Aplicacion PLANEA_Basica.pdf

4. Klopfer, E., Squire, K.: Environmental detectives: the development of an augmented reality platform for environmental simulations. Educational Technology Research and Development 56(2), 203-228 (2008)

5. Kaur, N., Pathan, R., Khwaja, U., Murthy, S.: GeoSolvAR: Augmented Reality Based Solution for Visualizing 3D Solids. In: 2018 IEEE 18th International Conference on Advanced Learning Technologies (ICALT), pp. 372-376 (2018)

6. Hanafi, H.F., Said, C.S., Wahab, M.H., Samsuddin, K.: Improving Students' Motivation in Learning ICT Course With the Use of A Mobile Augmented Reality Learning Environment. IOP Conf. Ser. Mater. Sci. Eng. 226(1), 012114, Aug. (2017)

7. Lucas, P., Vaca, D., Dominguez, F., Ochoa, X.: Virtual Circuits: An Augmented Reality Circuit Simulator for Engineering Students. In: 2018 IEEE 18th International Conference on Advanced Learning Technologies (ICALT), pp. 380-384 (2018)

8. Wu, H.K., Lee, S.W.Y., Chang, H.Y., Chong Liang, J.C.: Current status, opportunities and challenges of augmented reality in education. Computers \& Education, Volume 62, pp. 4149, ISSN 0360-1315, https://doi.org/10.1016/j.compedu.2012.10.024. (http://www.sciencedirect.com/science/article/pii/S0360131512002527) (2013)

9. Dimitrov, D.M., Rumrill Jr, P.D.: Pretest-posttest designs and measurement of change. Work 20(2), 159-165 (2003)

10. Wolfe, J.: The effectiveness games in strategic management course work. Simulation \& gaming 28(4), 360-376 (1997)

11. Hays, R.T.: The effectiveness of instructional games: A literature review and discussion. Naval Air Warfare Center Training Systems Division (No 2005-004) (2005)

12. Vogel, J.J., Vogel, D.S., Cannon-Bowers, J., Bowers, C.A., Muse, K., Wright, M.: Computer gaming and interactive simulations for learning: A meta-analysis. Journal of Educational Computing Research 34(3), 229-243 (2006)

13. Ke, F.: A qualitive meta-analysis of computer games as learning tools. In: Ferdig, R.E. (Ed.), Effective electronic gaming in education, Vol. 1, pp. 1-32 (2009)

14. Stizmann, T.: A meta-analytic examination of the instructional effectiveness of computer-based simulation games. Personnel Psychology 64(2), 489-528 (2010) [Also: Stizmann, T., Ely, K. A meta-analytic examination of the effectiveness of computer-based simulation games. ADL Research Lab (2011)]

15. Conversus: ¿Qué es la realidad aumentada? Retrieved from: http://www.cedicyt.ipn.mx/RevConversus/Paginas/RealidadAumentada.aspx (2016) 
Ramath: Mobile Application for Math Learning using Augmented Reality

16. Dirección General de Docencia de Pregrado: Aprendizaje Basado en Problemas, 8. Retrieved from http://www.sistema.itesm.mx/va/dide/inf-doc/estrategias/ (s.f.)

17. Kapp, K.M.: The Gamification of Learning and Instruction. In: Davis, M., Zelenko, M., Taff, R. (Eds.), San Francisco, CA. Pfeiffer (2012)

18. Abuín, J.R.: Regresión lineal múltiple. Estadística, Editor 32. In: Nicole, R.: The Last Word on Decision Theory. J. Computer Vision (2007)

19. Taylor, J.W. Exponential smoothing with a damped multiplicative trend. International journal of Forecasting 19(4), 715-725 (2003) 